Please return the prosi wich corrections. I any, as spevsily as possible to:

The Editor, The Faraday Society, 6 Gray's Inn Square. W C. I

This paper may not be published uncil it has been presented at the meeting.

No vertatum report of the Discussion will be taken Speakers should send to the Editor a summary of their ramarks for publication.

Conit. bi t.uns to the discussion will be published only If sent in writing to the Secreury of the Faraday Society, 6 Gray's ian Square, London. W.C. I belore

\title{
Pulse Radiolysis Studies of the Reactivity of the Solvated Electron in Ethanol and Methanol
}

\author{
by irwin A. Taub, Myran C. Sauer, Jr. and leon M. Donfman
}

Argonne National Laboratory, Argonne, Illinois, U.S.A.

Received 10th Jure, 1963

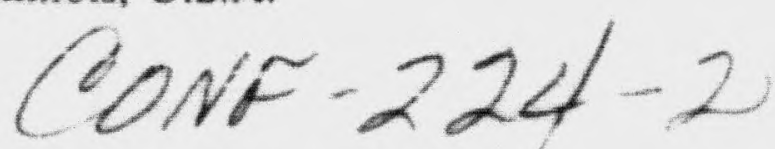

By means of the pulse radiolysis technique a short-lived transient species has been observed in irradiated dz-aerated ethanol and methanol, exhibiting an optical absorption throughout the visible and near infra-red. This transient is suggested to bo the solvated electron on the hasis of the nature of the spectrum, the reactivity with hydreger ion and with various organic electron acceptors, and the formation of munonegative ions of sonite of these acceptors.

The absolute rate constants have been Jetermined for the reactions of the solvated electron with hydrogen ion, oxygen and benzyl chloride in ethunol and methanol. The diphenylide ion was found $t w$ be short-lived in ethanol. The absolute rite constant for the first-order decay of the diphenylide ion has been determined

The theoretical considerations of eiectron solvation in polar liquids such as ammonia ' and water ${ }^{2}$ apply to other polar liquids. Thus in ethanol and methanol, for which the values of the static dielectric constant at room temperature are 25 and 33 respectively ${ }^{3}$ (large compared to unity) one may expect a priori that the physical process of electron solvation will take place. Measurements of the dielectric dispersion in these alcohols, ${ }^{4}$ which indicate that both hquids have a relatively high atomic polarization, as does water, lead to this conjecture.

The natural lifetime of the solvated electron, if solvation does occur, will then be determined largely by the specific rate of removal of the electron in chemical reactions with the solvent. The rates of these reactions with the solvent may vary widely from one liquid to another, as is evident from a comparison of the natural lifetime of the solvated electron in ammonia ${ }^{5}$ and in water. ${ }^{6}$ If this lifetime is sufficiently long the species may be amenable to direct observation.

Some evidence for electron solvation in organic glasses, ${ }^{7}$ consisting of compounds having lower dielectric constants than the alcohols, has been obtained in flash photochemical experiments with solutions of the alkali metals. These experiments have been extended to the liquid state. ${ }^{8}$ Observation of an optical absorption and formation of mononegative ions of solute molecules in $\gamma$-irradiated organic glasses, ${ }^{\circ}$ including ethanol, has been presented as evidence for electron solvation.

The possible role of electron solvation in the radiation chemistry of liquid ethanol has been discussed, 10 and a mechanism involving negative polarons has been suggested. Recently, experimental evidence 11 indicating that the solvated electron is a precursor of hydrogen in the radiolysis of methanol, has been obtained by the use of scavengers which are effective electron acceptors. 
The present paper is concerned with the application of the pulse radiolysis technique 12,13 to this question in the case of liquid ethanol and methanol. The primary objective has been the determination, by this fast reaction method, of the specific reactivity of an observed transient which, from its spectral and chemical characteristics is suggested to be the solvated electron.

\section{EXPERIMENTAL}

The technical details of the pulse radiolysis method have already been presented. ${ }^{13}$ Some additional details are given in the later reports 14, on ethanol and aqueous ethanol solutions. Only the briefest description will be presented here, along with those experimental conditions which are unique to the present investigation.

\section{PULSE IRRADIATION}

A $15 \mathrm{MeV}$ electron beam from the linac was used throughout. In the spectrophotographic experiments a $5 \mu \mathrm{sec}$ pulse was used. In the spectrophotometric experiments, in which some of the rate curves had a total duration of $2 \mu \mathrm{sec}$ or less, a $0.4 \mu \mathrm{sec}$ pulse was used. The pulse currents were in the range $40.150 \mathrm{~mA}$. A $0.4 \mu \mathrm{sec}$ pulse at $100 \mathrm{~mA}$ delivers a dose of approximately $1.4 \times 10^{17} \mathrm{eV} / \mathrm{g}$. The electron beam had an incident diameter of $16 \mathrm{~mm}$ and an emergent diameter of about $18 \mathrm{~mm}$ for a $4 \mathrm{~cm}$ long cell. The cells used were cylindrical quartz cells as in previous work.

\section{SPECTROPHOTOGRAPHY}

The four-fold reflection system with collinear analyzing light beam and electron beam ${ }^{13}$ was used throughout. The Jarrell-Ash $2.25 \mathrm{~m}$ grating spectrograph, f/24 was used. Eastman-Kodak spectroscopic plates. type 103-F, were used over the region $450-670 \mathrm{~m} \mu$. A single flash of the xenon flash lamp was sufficient to produce satisfactory spectra on these plates. Over the region $550-850 \mathrm{~m} \mu$, Eastman Kodak spectroscopic plates, type 1-N, were used. These plates were sensitized in aqueous ammonia followed by an alcohol wash and air-dried with a blower. Considerable difficulty was encountered in obtaining sensitized plates of uniform density, without blotching. Five flashes of the spectroflash lamp were needed to obtain spectra of satisfactory density with these plates for use on the densitometer.

SPECTROPHOTOMETRY

A I P28 photomultiplier tube was used to monitor the light from the steady lamp, which was an Osram mercury lamp, type HBO 107/1. The visible absorption was usually monitored at $5461 \mathrm{~A}$, although a few runs were also done at $5770-5790 \AA$. Since the absorption is extremely broad, a $5 \mathrm{~mm}$ aperture in front of the photomultiplier was used, giving a band width of $75 \AA$.

$$
\text { MATERIALS }
$$

The ethanol was U.S.I. Absolute Pure Ethyl Alcohol, U.S.P.-N.F. Reagent Quality, obtained from U.S. Industrial Chemicals Co. The methanol was Anhydrous Methyl Alcohol, Analytical Reagent, obtained from Mallinckrodt Chemical. The methanol was fractionally distilled in the following manner. About 11. methanol, to which had been added $1 \mathrm{ml}$ of conceutrated sulphuric acid and 4 to $5 \mathrm{~g}$ of 2.4-dinitrophenylhydrazine. was placed in the still pot of a Hasteloy B (\#1979) Podbielniak still, $8 \mathrm{~mm} \times 12$ in. After refluxing for about I h the still was run at maximum take-of rate and the first $110 \mathrm{ml}$ were discarded. The next $500-600 \mathrm{ml}$ were collected and used. This purification was found to be necessary since the distillation substantially increased the half-life of the solvated electron in degassed neutral solution. In the purified methanol, the half-life of the transient 
was fully an order of magnitude longer than for the rate curves for reaction with added solutes. The ethanol, in most runs, was used without further purification on the basis of the observed, relatively long. half-life of the transient in neutral solution. Some ethanol was purified with a drying agent prepared from $5 \mathrm{~g}$ of magnesium powder, $60 \mathrm{ml}$ of ethanol and $0.5 \mathrm{~g}$ of iodine. To this was added $900 \mathrm{ml}$ of ethanol which was then refluxed for $1 \mathrm{~h}$ and then distilled. This procedure reportedly reduces the water content to less than $002 \%$. In the one case in which runs were carried out with this purified ethanol there was no difference in the measured rate constant.

Other compounds used in this work were: benzyl chloride, CP Baker's Analyzed Reagent: diphenyl from Matheson Co.: naphthalene, Baker's Analyzed Reagent : anthr: cene, Scmtillation Grade from Reilly Tar and Chemical Corp

The degassing technique was the same as described previously, ${ }^{6}$ which involved sealing off the cells under vacuum, except for the experiments with oxygen in solution. For the solutions containing oxygen, for which it was necessary to determine the concentration of dissolved oxygen, it was desirable to use a cell having no gaseous volume. Consequently, cells having capillary leads and ground glass caps, adapted from a description of an irradiation syringe, 15 and using the degassing method described there, were used exclusively in the rate studies with oxygen.

The solutions containing oxygen were made up by admitting a known pressure of oxygen to the degassed alcohol maintained at about $-78 \mathrm{C}$. The solution was then brought back to roon temperature and the cells. which had previously been flushed with helium were filled by forcing the liquid from the degassing bulb is into the cells under helium pressure. These cells had no gaseous volume, being filled entirely with the alcohol solution.

Acidified alcohol solutions, which were used in determining the rate of reaction of the solvated electron with the hydrogen ion, were made up from $\mathrm{HCl}$ and $\mathrm{H}_{2} \mathrm{SO}_{4}$ in the follow. ing manner. Anhydrous $\mathrm{HCl}$ was bubbied through ethanol for about $15 \mathrm{~min}$ and titrough methanol for about $5 \mathrm{~min}$ to maki; up stock solutions which were roughly $1-2 \mathrm{M}$. Solutions where then made up by micro-pipetting from this stock solution to give solutions in the concentration range $10^{4-1 g^{-5}} \mathrm{M}$ Sulphuric acid stock solutions were made up from a weighed quantity of costentrated acid. There was thus an uncertainty of a few percent in the stiphuris acid conten. The solutions for kinetic studies were similarly made up by micrc-pipetting from the stock solution. In all cases, appropriate corrections were applied to the degassed solutions for volume loss during degassing

The benzyl chloride stock solutions were made up both gravimetrically and volumetrically. In cakulating the concentration of benzyl chloride in the ditute solutions the volume correction for solvent loss in degassing was taken into account.

$$
\text { ANALYIICAL }
$$

I he oxygen content of the oxygenated solutions was determined by extraction of the gits from the alcohol in a vacuum system, followed by analysis on a gas chromatograph Ihe oxygen and dissolved helium were removed by means of a Toepler pump and forced into a -tube between two stopcochs. This gas was then analyzed chromatographically on a column packed with molecular sieve $13 \mathrm{X}$ which separated oxygen and nitrogen. The amount of nitrogen was an indication of the extent of air leakage into the cell. This gener. ally amounted to less than $5 \times 10^{\circ} \mathrm{M} \mathrm{O}_{2}$ In several runs, duplicate cells were filled and the oxygen onncentration determined both before and after a run

The acid content of the stock solutions was determined by diluting the stock solution 100 -fold in water the resulting aqueous solution being roughly $2 \times 10^{2} \mathrm{M}$ ) and determining the $\mathrm{pH}$ with a Radioneier mudet $4 \mathrm{pH}$ meter.

\section{RESULIS AND DISCUSSION}

The experimeutal observations which have been carried out at the time of pre. paration of this paper include the spectrophotographic recording of the tuansient 
spectrum in deaerated ethanol and methanol, the determination of the abolute rate constants for the reactions of the transient with hydrogen ion. oxygen and benzyl chloride in both akohols, and an investigation of the reactions in solutions containing electron acceptors such as naphthalene and diphenyl. In the last system these studies involve not only the primary transien but also obser:ation of transient species formed from the solute molecules.

\section{SPIE IOL}

Spectrophotographic observations made during. and within 2 of 3 usec after a 5 pece electron pulse (current $-80 \mathrm{~mA}$ ) show a transient optical absorption in deaerated ethanol extending from about $350 \mathrm{mpi}$ to our long-wavelength limit of observation at about $860 \mathrm{~m} \mu$. The spectrum shows a broak peak at about $696 \mathrm{my}$ with a shoulder at about $520 \mathrm{~m} \mu$ as determined from densitometer tracings. The location of these maxima must be regarded as approximate since " $\mathrm{H}$ and $\mathrm{D}$ " corrections have not been applied to the plates. Moreover, the peak is not at all sharp and the most obvious feature of the spectrum is the absence of any pronounced structure. Deaerated methanol also shows a strong absorption in the visible, but the location of any maximum has no: yet been established.

The half-life of the transient in deaerated neutral ethanol following a $0-4 \mu$ sec pulse at $110 \mathrm{~mA}$ (which corresponds to $1.5 \times 10^{-7} \mathrm{eV} g$ ) is approximately $3 \mu \mathrm{sec}$ The decay curve under these conditions is shown in fig. I. This curve undoubtedly contains a contribution from the reaction with the counter-ion. The lifetime in basic solution is considerably longer, as indicated in a single experiment, but a com. plete investigation of the natural lifetime in strongly basic solution, such as we have reperted for the hydrated electron, ${ }^{\circ}$ has yet to be carried out. From the rate curves we estimate the product of the molar extinction coefficient at $5461 \AA$ and the $G$-value, 66 . These estimates give

$$
\begin{aligned}
& \text { ethanot } \quad G_{e}=11015 \times 10^{4} \mathrm{M}^{-1} \mathrm{~cm}-1 \mathrm{~mol} .100 \mathrm{eV} \\
& \text { methanol } \quad \therefore G_{\text {sed }}=0.8101 .5 \neq 10^{4} \mathrm{M}^{\prime} \mathrm{cm}-\text { mol. } 100 \mathrm{cV}
\end{aligned}
$$

In the ibsence of information on $G_{e}$, we are unable to estimate the ascilator strength

The region of the absorption spectrum and the maximum at about $696 \mathrm{~m} \mu$ are very similar to the absorption spectrum of the hydrated electron in water. 10.1 . The transient absorption is eliminated in acidic alcolol solutions. Moreover, the specific reactivities of the transient with hydrogen ion and with oxygen are nearly identical to the reactivities of the hydrated electron 6. Is with these stable species. The transient racts rapidly with clectron acceptors such as benzyl chloride, naphthalene and diphenyl. For diphenyl, which has been studied in detat, the product has been identified as the nononcgative ion. These observations indicate that the transient is t' solvated electron. "set.

$$
\text { MATE CONSTANTS }
$$

The absolute rate constants which have been determined are shown in table I In all cases, the rate curves have been observed at a concentration of the added reactant such that the decay rate of the electron is fully an order of magaitude faster that in the absence of the reactant, and is furthermore pseudo-fint-order 


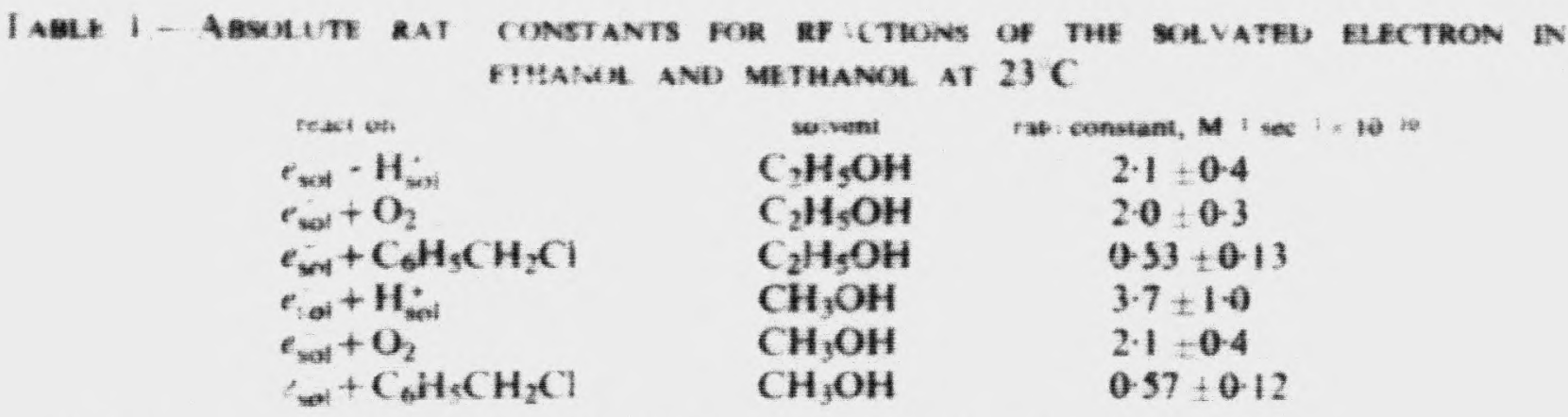

The reaction of the solvated electron in ethanol with oxygen,

$$
\mathrm{t}_{\text {nut }}+\mathrm{O}_{2}=\mathrm{O}_{2} \text {, }
$$

has been determined over a concentration range of oxygen from $4 \times 10^{5}$ to $11 \times$ $10^{-5} \mathrm{M}$. The initial electron concentration was varied 2-fold. Typical decay curves are showr in fig. 2 and fig. 3 for the reaction in ethanol. A typical first-order rate lan test of such rate curves is stown in fig. $4 \mathrm{n}$ which is presented a plot of the logarithm of the optical density as a function of time. This is a representation of

$$
\log _{10} D^{t}=\alpha^{\prime} 1 / 2 \cdot 303 \text {, }
$$

the integrated form of the pseudo first-order differential rate expression, where $D^{\prime}=\log _{10}\left(I_{t} / I_{t r}\right)$ and $k$ is the pseudo first-orcer rate constant. The results give rat: constants of $(20 \pm 0.3) \times 10^{10} \mathrm{M}^{1} \mathrm{sec}^{-1}$ and $(2.1 \pm 0.4) \times 10^{10} \mathrm{M}^{-1} \mathrm{sec}^{-1}$ at $2 \% \mathrm{C}$ for the reactions in ethanol and methanol respectively. The slightly larger tror limit with methanol stems largely from the fact that only three separate determinations were made compared with ten with the ethanol. These rate constants are essentially the same as that of the hydrated electron with oxygen, for which a value of $1.9 \times 10^{10} \mathrm{M}^{-1} \mathrm{sec}-1$ has been reported. 18

The rate of reaction with hydrogen ion was determined over a concentration range of the hydrogen ion of $0.24 \times 10^{4}$ to $1.2 \times 10^{-4} \mathrm{M}$ in ethanol and $0.4 \times 10^{4}$ to $\mathrm{I} \times 10^{-4} \mathrm{M}$ in methanol using $\mathrm{HCl}$. A somewhat smaller range was covered using $\mathrm{H}_{2} \mathrm{SO}_{4}$ The hydrogen ion concentration in the $\mathrm{HCl}$ solutions was calculated on the assumption of complete disscciation ${ }^{19}$ of this acid in the alcohols at the low concentrations used. In ethanol the absolute rate constant for reaction of the electron with hydrogen ion is found to be $(2 \cdot 1 \pm 0 \cdot 4) \times 10^{10} \mathrm{M}^{-1} \mathrm{sec}$. The sulphuric acid solutions, on the assumption of only the first dissociation to $\mathrm{H}$ and $\mathrm{HSO}_{4}$. give $(2 \cdot 2 \pm 0 \cdot 3) \times 10^{10} \mathrm{M}{ }^{+} \mathrm{sec}$ in agreement with this value. The rate constant for the reaction in methanol was found to be $(3.7 \pm 1.0) \times 10^{10} \mathrm{M}^{-1} \mathrm{sec}^{-1}$. We cannot explain the apparent higher rate constant for the reaction with the hydrogen ion in methanol. A small correction for the contribution by counter-ion, amounting to about $3^{\circ}$ was applied here as vell as to the reaction rates with oxygen.

The electron reacts rapidly with benzyl chloride. The rate constants in ethanol and methanol were found $t\left(0^{2}\right.$ be $(5 \cdot 3 \pm 1 \cdot 3) \times 10^{\circ} \mathrm{M}^{-1} \sec ^{-1}$ and $(5 \cdot 7+1 \cdot 2) \times 10^{\circ}$ $M$ sec 1 respectively. at $23 \mathrm{C}$. In these solutions we find the benzyl radical as an intermed, te. as extablished by its transient absorpuon spectrum, in agreement with previus work. The reations of this transient are under investigation in our laboratory. In solutions of triphenyl chloromethane we similarly find the triphenyl methyl radical

\section{AROMATIR ANIONS}

The transient absorption spectra and kinetics in ethanol solutions of aromatic molecules such as naphthalene. diphenyl and anthracene are being investigated. 
The initial objective was to obtain supporting evidence for the identity of the solvated electron through the observation of the mononegative ions of the hydrocarbons, which are presumably formed (as for the diphenylide ion) in the reaction

$$
e_{\text {sol }}+\mathrm{C}_{12} \mathrm{H}_{10}=\mathrm{C}_{12} \mathrm{H}_{10} \text {. }
$$

The ultra-violet and visible absorption spectra of these mononegative ions are known.21,22 The solvated electron reacts rapidly with these electron atceptors. and with the diphenyl we have identified the diphenylide ion from the peak at $400 \mathrm{~m} \mu$ and the wide band in the visible showing two peaks at 610 and $635 \mathrm{~mm}$. This corresponds with the spectrum published, 21 in which peaks are shown at 400,617 and $637 \mathrm{~m} \mu$. As expected since the electron is the precursor. these transients are eliminated in acid solution.

In the experiments with diphenyl and naphthalene, the simultaneous decay of the absorption at $5461 \mathrm{~A}$ and the formation of a second transient at $3130 \AA$ has been recorded using a double photomuluplier arrangement. Such simultaneous disappearance and appearance curves are shown in fig. 5. The decay curve at $5461 \AA$ contains a contribution from both the solvated electron and the diphenylide ion, the former presumably predominating at low concentration of diphenyl, $a$. $10^{-5} \mathrm{M}$, with an increasing contribution by the diphenylide won as the concentration is increased. The formation curve at 313$) \bar{A}$ consists primarily of an absorption of a transient formed from the diphenylide ion. probably by proton capture from the solvent to form a hydrogen adduct. Such a process has been suggested to occur in methanol solution. 11 The near identity in the rates of the formation and disappearance curves in fig. 5 clearly establishes the precursor relationship of the transients.

The observation, made both spectrographically and spectrophotometrically at $4047 \mathrm{~A}$, that the diphenylide ion in ethanol is short-lived is in contrast with the long lifetime of the aromatic anons in solvents such as tetrahydrofurar. This difference in lifetime is attributed to the protonic character of the ethand. The decay of the diphenylide ion in ethanol is first-order. The rate constant for the reaction, $\mathrm{C}_{12} \mathrm{H}_{13}+\mathrm{C}_{2} \mathrm{H}_{5} \mathrm{OH}$, determined at diphenyl concentrations greater than $10^{-3} \mathrm{M}$, was found to be $(4 \cdot 1 \pm 0.7) \times 10^{\circ} \mathrm{sec} 1$ at $23 \mathrm{C}$ expressed as a first-order constant. Work on the protonation reactions of other aromatic anions is continuing.

We are indebted to a number of our colleagues for technical assistance. In particular, we thank Mr. Douglas Harter in this regard. The linac was operated by Mr. B. E. Clifft. We are grateful to Dr. R. Platzman and Dr. W. H Hamill, with whom we have had a number of illuminating and stimulating discussions.

Davidow, Thurn. Expt Theor Fizik, 1948, 18, no 10, 413

2 Platzman, Bastr Mechanisms in Radhohologv (Nat. Acad Sol Publ. no, 305) 1954,22

Buckley and Marvott. Nat Bur Sratad fire 589,1958

4 Lane and Saxton. Proc Roy. Sor 4, 1952, 213, 400

symons. Quart. Rev., 1959, 13, 99.

o Dorfman and Taub. $J$. Amer, (hem Sor 1961, 85, in press.

Linchite, Berry and Schweitzer, I. Amer. Chem. Soc. 1454, 76, 5833

* Eloranta and Linstiste, $J$. Chem Physes, 1963, 38, 2214

* Ronayne, Guarino and Hamill, $J$. Amer. Chem. Soc, 1962, 84, 4230

10 Hayon and Weiss, $j$. Chem Sor , 1961,3902

1: Baxendale and Mellows, $f$ tmer. (hem. Sor, 1961, 83, 4720 
12 Matheson and Dorfman, J. Chem. Physucs, 1960, 32, 1870.

13 Dorfinan, Taub and Buhler, J. Chem. Physics, 1962, 36, 3051

if Tan't and Dorfman, J. Amer. Chem. Sor . 1962, 84, 4053.

"Senvar and Hart, Pros 2nd U.N. Int. Conf. Peaceful Uses of Alomit I , ryy, 1958, 29, 19

16 Boag and Hart, Nature, $1963,107,45$.

It Hor and Boag. J. Amer. Chem. Sac. 196*, 04,4090

is Cordon, Hart, Matheson, Q-tam and thomas, J. Amer. Chem. Sor., 1963. 85, 1375

MacInnes, The rewoles of Electrochemustry (Reinhold Publishing Corp. New Yofk, 1939). p. Is

20 Mor arthy and Maclachlan, Trans. Furaday Soc., 1960, 56, 1187

21 Halk. Moitink and Schreurs. Rec. Irat. chim., 1957, 76, 813.

22 Paul. Lipkin and Weissman, J Amer. Ctem. Soc., 1956, 78, 116

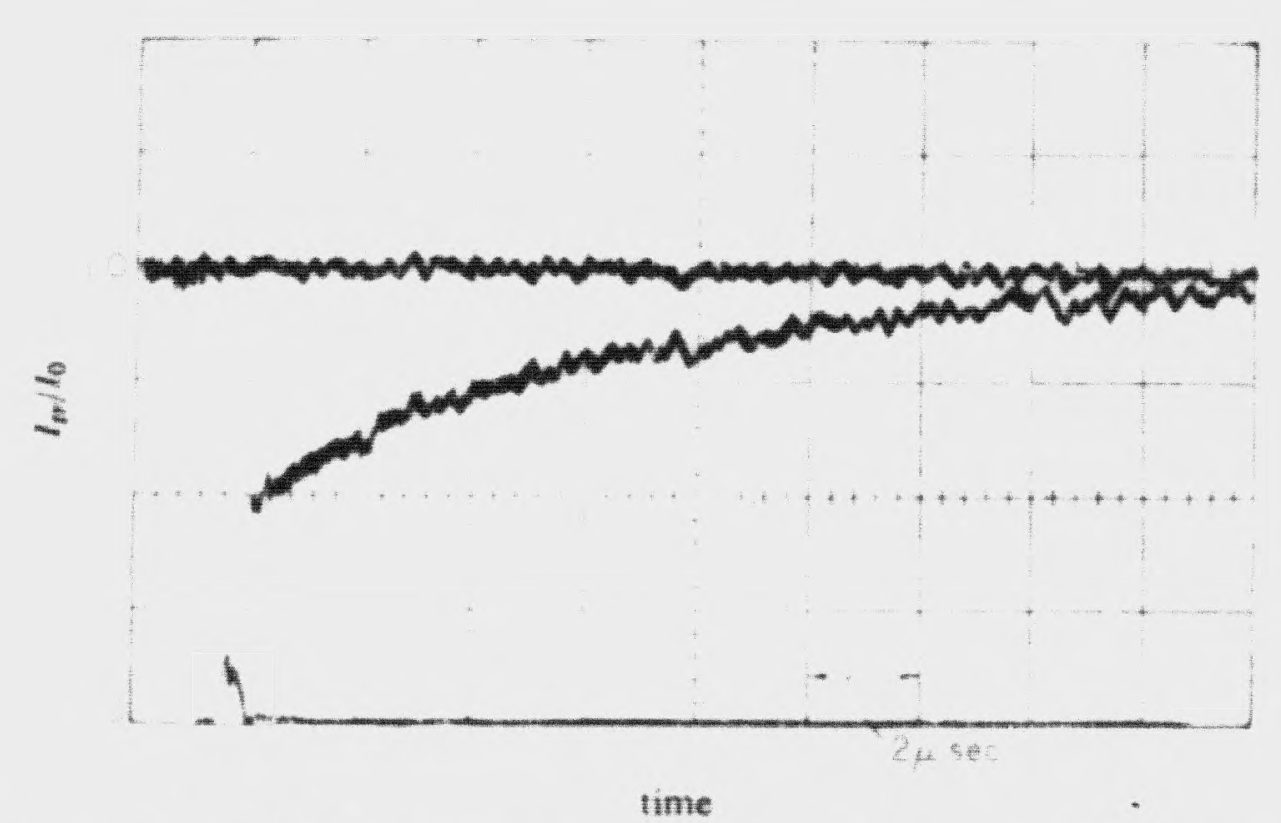

Fa. 1-Rate curve for the disappearance of the solvated electron in deacrated rure ethanol at $5461 \AA$ following a $0.4 \mu$ ase electron pulse.

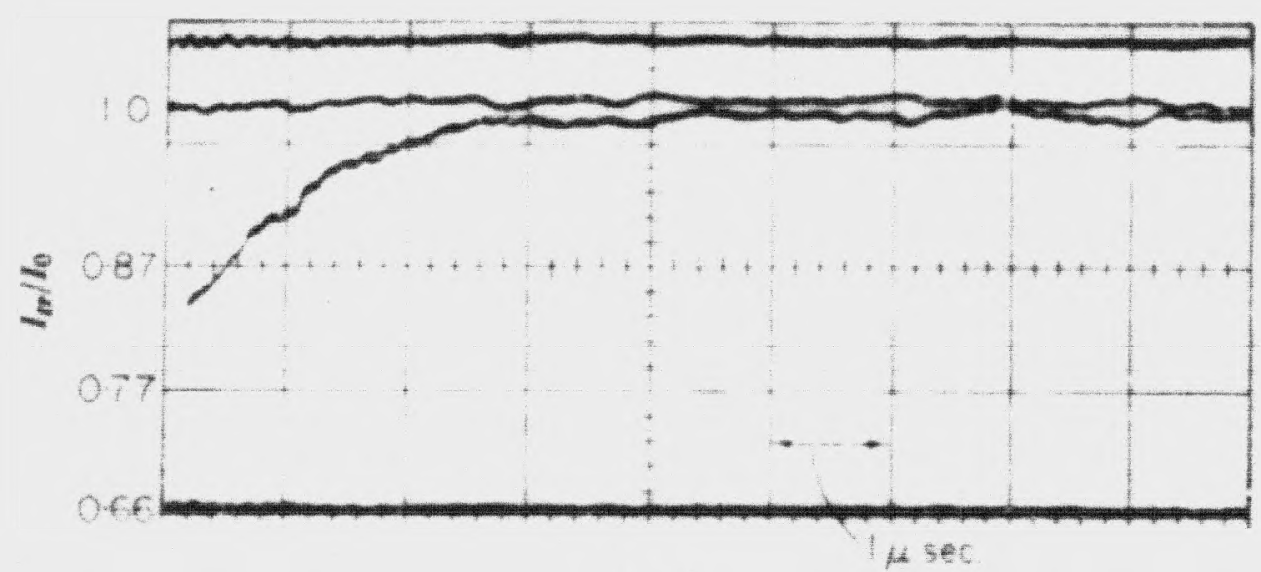

tume

Iw. 2 Rate curve for the reactum of the syivated electron with oxygen in ethanol following a 0.4 usec pulse at $60 \mathrm{~mA}$. The truttal oxygen concentration was $4.6=10^{5} \mathrm{M}$. The rate curve was obtained at $5461 \AA$

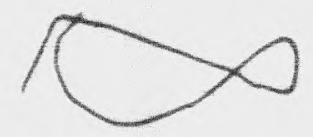


FARADAY-TAUB et al -5A

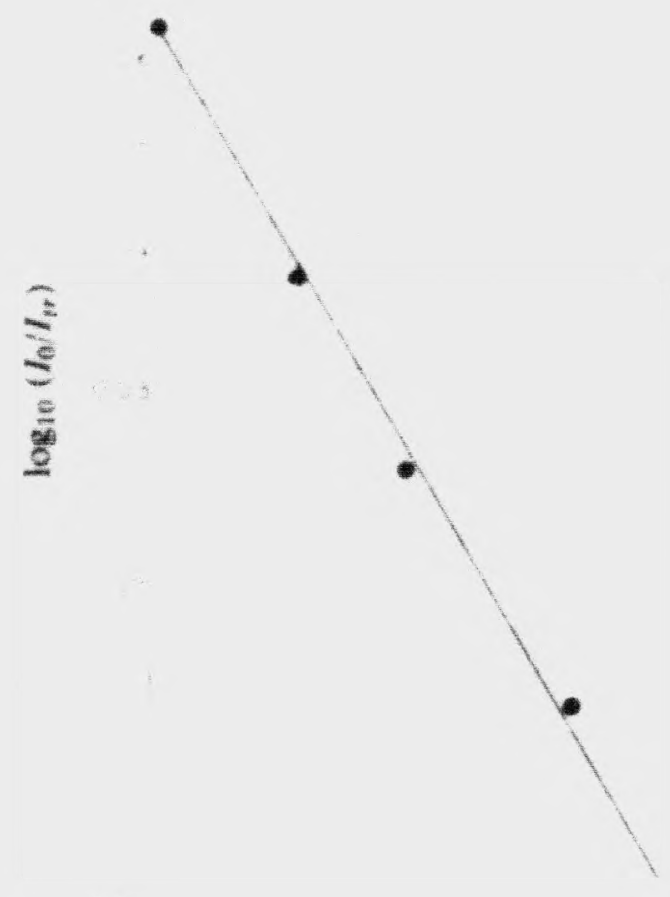

lime, $\mu \mathrm{sec}$

Its. 4 - Iest of firstorder rate lau for the reaction of the solvated electron with oxygen in ethanol This is a logarithmic plot of the optical density as a function of time.

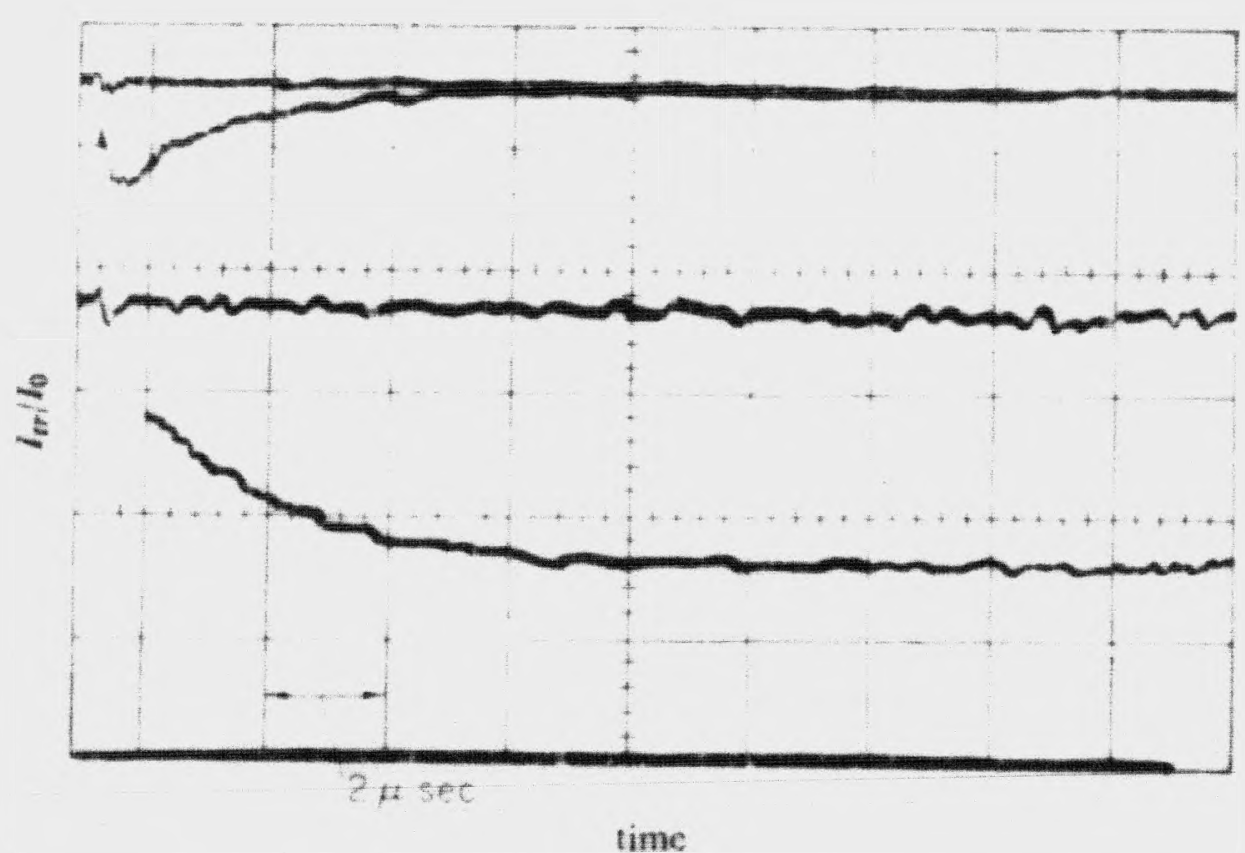

Fir. 5 Sinultaneous disappearance and forn.ation curves, following a $0.4 \mu \mathrm{sec}$ pulse, at $5461 \mathrm{~A}$ (upper curve) and $3130 \mathrm{~A}$ (lower curve) in ethand suluitun of diphenyl. The upper curve contains a contribution from both the electron and the diphenytide ion. The lower curve represents a transient formed from the diphenylide ton. 


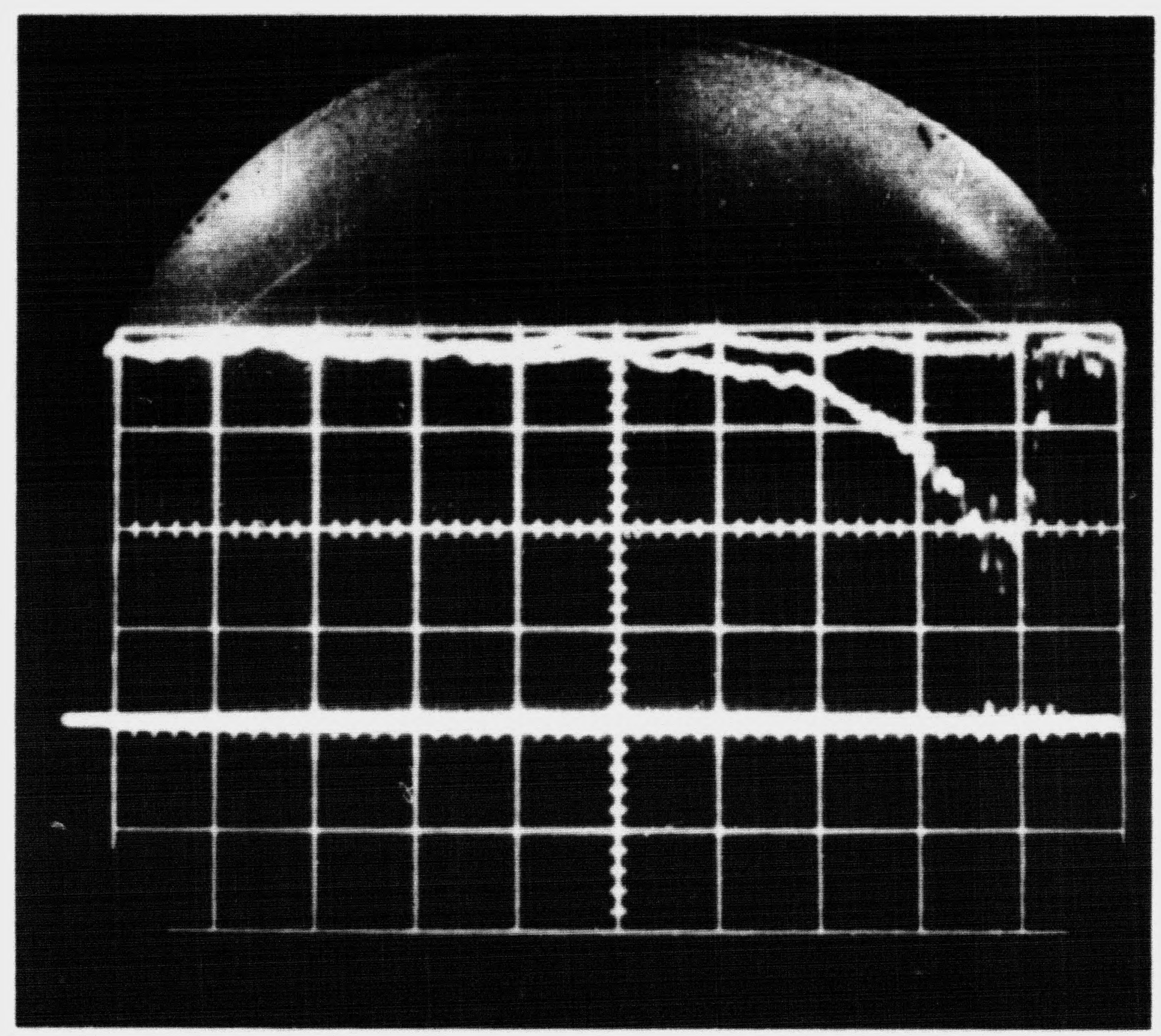

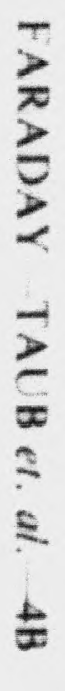

Fle. 3. Rate curve for the reaction of the solsated electrom whowgen in ethanol The sweep-rate is 1 , weo large divison The cifve was blatned at 5461 A The pulse current is approsumately $80 \mathrm{~mA}$
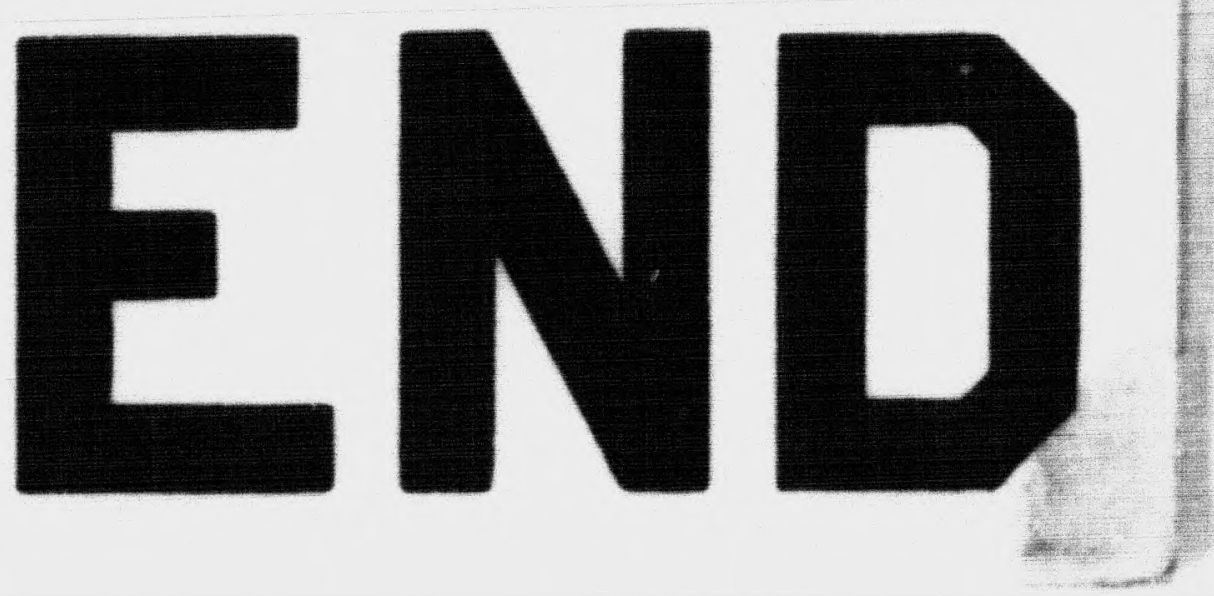